\title{
Fotossíntese, Reservas Orgânicas e Rebrota do Capim-Mombaça (Panicum maximum Jacq.) sob Diferentes Intensidades de Desfolha do Perfilho Principal ${ }^{1}$
}

\section{Carlos Augusto de Miranda Gomide ${ }^{2}$, José Alberto Gomide ${ }^{3}$, Carlos Alberto Martinez y Huaman ${ }^{4}$, Domingos Sávio Campos Paciullo ${ }^{5}$}

\begin{abstract}
RESUMO - Buscando-se avaliar morfofisiologicamente a rebrota do capim-mombaça, quatro desfolhas foram impostas ao perfilho principal, sendo estudado o comportamento da planta em termos da taxa de expansão da área foliar, crescimento do sistema radicular, nível de carboidratos totais não estruturais (CTNE) da raiz e do colmo, taxa de crescimento relativo (TCR), taxa de assimilação líquida (TAL) e razão de área foliar (RAF) às idades de 2, 5, 9 e 16 dias após as desfolhas, bem como da taxa fotossintética máxima às idades de 2, 6 e 13 dias das folhas remanescentes à desfolha. As desfolhas foram as seguintes: remoção de todas as lâminas foliares (desfolha total), a remoção da lâmina da folha adulta mais jovem (desfolha superior), a remoção das lâminas das duas folhas adultas mais velhas (desfolha inferior) e controle (sem desfolha), juntamente com o corte dos demais perfilhos, realizado a $8 \mathrm{~cm}$ do solo. Foram observadas cinco repetições por tratamento, segundo o delineamento inteiramente casualizado. As folhas adultas não diferiram quanto às taxas fotossintéticas máximas, que exibiram aumento nos primeiros dias após a desfolha, e queda aos 13 dias. A desfolha reduziu os teores de CTNE da base do colmo, principalmente nas plantas sob desfolha total. Comprometimento do crescimento do sistema radicular e do teor de CTNE das raízes foi observado nas plantas sob desfolha total, que também tiveram sua TCR reduzida nos primeiros dias de rebrotação. Entretanto, o aumento na RAF possibilitou a estas plantas recuperação da TCR e alta taxa de expansão da área foliar, igualando a área foliar das demais plantas aos 16 dias de rebrota.
\end{abstract}

Palavras-chave: área foliar, balanço de carbono, respiração, reservas, taxa de crescimento, partição de assimilados

\section{Photosynthesis, Organic Reserves and Regrowth of Mombaçagrass (Panicum maximum Jacq.) under Different Defoliation Intensities of the Main Tiller}

\begin{abstract}
An experiment was carried out to evaluate morphophysiological aspects of Mombaçagrass growth after defoliation. Defoliation treatments were performed when the number of green completely expanded leaves on main tiller had stabilized around 3. Four defoliation treatments were imposed to the main tiller: T1 - no defoliation, T2 - total defoliation, T3 - removal of the last expanded leaf and T4 - removal of the two lowest expanded leaves. In all cases primary tillers were completely defoliated by cutting at $8 \mathrm{~cm}$ height from soil level. The variables assessed were: leaf expansion rate, root growth, relative growth rate (RGR), net assimilation rate (NAR), leaf area ratio (LAR) at the ages of 2, 5, 9 and 16 days regrowth, stem and root total non structural carbohydrate content and maximum leaf photosynthesis rate at the ages of 2, 6 and 13 days regrowth. There were five replications, according to a completely randomized design. There was no difference in the photosynthetic rate among the 3 expanded leaves considered at defoliation time. Photosynthetic rate of any leaf remaining after defoliation increased initially, but had declined by the $13^{\text {th }}$ day of regrowth. Stem total non-structural carbohydrates content dropped in response to leaf removal, mainly in the total defoliation treatment which also brought about reduced root growth. Still, the completely defoliated plants had restored their RGR by the $16^{\text {th }}$ day regrowth due to high leaf area expansion rate and leaf area ratio.
\end{abstract}

Key Words: assimilate partitioning, carbon balance, growth rate, leaf area, respiration, reserves

\section{Introdução}

A remoção da parte aérea, pelo corte ou pastejo, representa um estresse para as plantas, cuja magnitude depende da intensidade da desfolha. A desfolha reduz a intercepção de luz e, também, a fotossíntese líquida do dossel, bem como a quantidade de compostos orgânicos de reserva e o crescimento de raízes (Davidson \& Milthorpe, 1966).

Para muitos, a queda no teor dos carboidratos de reserva, nos primeiros dias de rebrotação após desfolha, seria um indício de sua participação no novo crescimento. Segundo alguns autores, a participação destes compostos restringe-se principalmente à res-

\footnotetext{
${ }_{1}$ Parte da Tese de Doutorado do primeiro autor, Financiado pela FAPEMIG

2 Pós-Doutorando da UNESP-Jaboticabal - Bolsista FAPESP - UNESP Via de Acesso Prof. Paulo Donato Castellane, s/n, Dep. Zoot., Jaboticabal-SP, CEP: 14883-412 (cagomide@fcav.unesp.br)

${ }^{3}$ Pesquisador IA do CNPq - DZO, Campus da UFV, Viçosa-MG (jagomide@ufv.br)

${ }^{4}$ Professor de Fisiologia Vegetal da USP, Ribeirão Preto-SP (carlosamh@ffclrp.usp.br)

5 Bolsista Recém-Doutor do CNPq/CNPGL - Juiz de Fora-MG (dscp@terra.com.br)
} 
piração de manutenção (Marshall \& Sagar, 1965; Davidson \& Milthorpe, 1966). Schnyder \& De Visser (1999) observaram que o carbono presente nos aminoácidos representou $60 \%$ do fluxo líquido das reservas durante os dois primeiros dias da rebrotação de azevém perene. Para estes autores, as reservas de carboidratos solúveis desempenham papel secundário para o crescimento de perfilhos após o corte, embora relatem correlação positiva entre a recuperação das plantas e o conteúdo desses compostos ao tempo do corte.

Estudos com carbono marcado $\left(\mathrm{C}^{14}\right)$ têm revelado a presença de radioatividade em tecidos formados após o corte, evidenciando o papel das reservas orgânicas. Resultados com Festuca pratensis, exposta ao $\mathrm{C}^{14} \mathrm{e} \mathrm{C}^{13}$, mostram transporte não só da base do colmo, mas também das raízes em favor dos novos tecidos, uma vez que a quantidade encontrada na parte aérea foi maior que o potencial da base do colmo (Johansson, 1993).

Entretanto, a importância dos carboidratos de reserva, como fator de rebrotação das plantas, limitar-se-ia aos primeiros dias de recuperação, enquanto não se expandem as primeiras folhas (Ward \& Blaser, 1961; Davidson \& Milthorpe, 1966; Fulkerson \& Slack, 1994; Schnyder \& De Visser, 1999).

À fotossíntese atual atribui-se o papel mais importante na promoção de um novo crescimento. Contudo, sua participação está condicionada à presença de área foliar que escapa ao corte ou a uma rápida emissão de novas folhas. O trabalho clássico de Brougham (1956) ilustra a estreita relação entre a área foliar e a velocidade de recuperação após desfolha.

Donaghy \& Fulkerson (1997), comparando o crescimento de Lolium perenne na luz e no escuro sob diferentes frequiências de desfolha, concluíram que a participação dos assimilados na nova área foliar foi de $66 \%$, contra $33 \%$ computado às reservas. Para Ward \& Blaser (1961), a taxa de rebrota de Dactylis glomerata foi creditada tanto aos carboidratos de reserva quanto à área foliar remanescente.

As folhas de um perfilho que escapam à desfolha são, na maioria das vezes, as mais velhas, com pequena capacidade de assimilação (Woledge \& Leafe, 1976); entretanto, alguns autores observaram aumento na eficiência fotossintética destas folhas após o corte (Delting et al., 1979; Painter \& Delting, 1981, Davies, 1974), a chamada fotossíntese compensatória (Richards, 1993). Tal efeito, porém, não foi observado em plantas de cevada submetidas à desfolha leve (Ryle \& Powell, 1975). Para esses autores, a alteração no padrão de alocação em favor das folhas em expansão foi a principal razão de uma rápida recuperação, fazendo com que a taxa de crescimento relativo não apresentasse diferença entre as plantas cortadas e aquelas mantidas intactas.

A partição de assimilados, oriundos da fotossíntese ou previamente armazenados, entre os diferentes órgãos da planta, é função das prioridades ditadas pela relação fonte/dreno e depende, entre outras coisas, das condições de manejo (Davies, 1974; Ryle \& Powell, 1975; Johansson, 1993), do estádio de desenvolvimento (Williams, 1964) e da época do corte (Frankow-Lindberg, 1997).

Segundo Davies (1974), para quem a taxa de aparecimento de novas folhas é uma boa caraterística para a avaliação da capacidade de rebrotação, a remoção da lâmina da folha recém-expandida causou maiores prejuízos à taxa de aparecimento e de crescimento relativo de novas folhas e ao perfilhamento de plantas de azevém perene.

A avaliação mais criteriosa da rebrotação de gramíneas provê condições para o conhecimento mais seguro dos mecanismos envolvidos na recuperação após o corte ou pastejo, auxiliando, assim, o entendimento dos efeitos de práticas de manejo, embora, para tanto, seja necessária a criação de condições não experimentáveis na prática, mas de grande importância acadêmica para o entendimento do processo. Objetivou-se com este trabalho, avaliar os mecanismos morfofisiológicos que interferem na rebrotação do capim-mombaça em função de diferentes intensidades de desfolha do perfilho principal.

\section{Material e Métodos}

O experimento foi desenvolvido em vasos em Casa de Vegetação da Unidade de Crescimento de Plantas do Departamento de Biologia Vegetal da UFV, no período de 08-03 a 14-05-99.

O solo utilizado foi um Latossolo Vermelho-Escuro, textura argilosa, com as seguintes características: pH em água -5,9; P e K - respectivamente, 7,4 e 107,0 mg.dm ${ }^{-3}$; alumínio - 0,0 cmolc. $\mathrm{dm}^{-3} ; \mathrm{Ca}+\mathrm{Mg}$ $-4,1$ cmolc. $\mathrm{dm}^{-3} ; \mathrm{H}+\mathrm{Al}-3,3$ cmolc. $\mathrm{dm}^{-3}$; CTC efetiva $-4,37 \mathrm{cmolc} \cdot \mathrm{dm}^{-3}$; e saturação de bases $57 \%$. Antes do enchimento dos vasos, o solo foi enriquecido com $200 \mathrm{mg} \cdot \mathrm{dm}^{-3}$ de fósforo, usando-se superfosfato simples.

Sementes de capim-mombaça foram distribuídas

R. Bras. Zootec., v.31, n.6, p.2165-2175, 2002 
em caixas de areia para germinação. Vinte dias após a emergência, foram selecionadas plantas vigorosas e uniformes, que foram transplantadas para vasos plásticos com capacidade para um quilo de solo, colocando-se uma planta por vaso.

Após o transplantio, fez-se a fertilização nitrogenada e potássica, correspondendo a $30 \mathrm{mg} \cdot \mathrm{dm}^{-3} \mathrm{de} \mathrm{N} \mathrm{e} \mathrm{K}$, via solução nutritiva de sulfato de amônia e cloreto de potássio. Tal procedimento foi repetido semanalmente durante a condução do ensaio, sempre associado à irrigação diária dos vasos.

Aos 35 dias após a emergência, quando a maioria das plantas apresentavam um número estável de três folhas verdes completamente expandidas, correspondendo às folhas de nível de inserção 7,8 e 9 , procedeu-se à imposição dos tratamentos. Nesta ocasião, as plantas apresentavam de 8 a 9 perfilhos primários.

Quatro intensidades de desfolha foram aplicadas ao perfilho principal das plantas: o controle, em que o perfilho principal foi mantido intacto; a desfolha superior, eliminando a lâmina foliar da folha adulta mais jovem; a desfolha inferior, que eliminou as lâminas foliares das duas folhas adultas mais velhas; e a desfolha total, que eliminou toda a área foliar do perfilho principal. Em todos os tratamentos, inclusive no controle, a folha emergente do perfilho principal foi eliminada, e os demais perfilhos cortados a $8 \mathrm{~cm}$ do solo. A Figura 1 ilustra o esquema de desfolhas.

Durante os 16 dias seguintes à imposição dos tratamentos, foram avaliados, às idades de 2, 5, 9 e 16 dias, o peso do sistema radicular, o peso e a área de cada folha remanescente, a expansão das novas folhas, bem como os índices instantâneos de crescimento: taxa de crescimento relativo (TCR), taxa assimilatória líquida (TAL) segundo Radford (1967), e a razão de área foliar ( $\mathrm{RAF}=\mathrm{TCR} / \mathrm{TAL})$.

Todo o material colhido foi levado ao laboratório, separado e secado a $65^{\circ} \mathrm{C}$ em estufa de ventilação forçada por 72 horas. As lâminas foliares, separadas

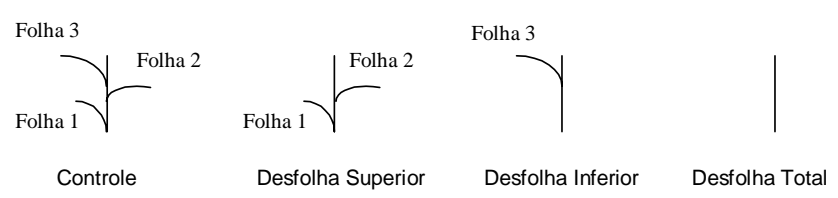

Figura 1 - Representação das desfolhas impostas ao perfilho principal do capim-mombaça.

Figure 1 - Representation of defoliation treatments of the main tiller of Mombaçagrass. por nível de inserção, tiveram sua área medida em sistema de análise de imagem - DIAS (Digital Image Analysis Systems, Delta-T, Cambridge, Inglaterra), sendo em seguida colocadas em estufa para secagem e obtenção dos respectivos pesos.

Foram observadas cinco repetições por tratamento, sendo utilizados, portanto, 80 vasos (4 desfolhas x 4 idades x 5 repetições), em um delineamento inteiramente casualizado. Cinco outros vasos foram acrescentados para colheita ao tempo da imposição dos tratamentos, o dia zero.

No dia anterior à imposição dos tratamentos, mediuse a taxa fotossintética de cada uma das quatro folhas do perfilho principal (as três completamente expandidas e a emergente), sob diferentes intensidades luminosas, para ajustar-se a curva de resposta à luz. As intensidades luminosas estabelecidas foram: 0, 250, 400, 500, $1300,1700 \mathrm{e} 2700 \mathrm{mmol} . \mathrm{m}^{-2} \cdot \mathrm{s}^{-1}$; conseguidas mediante a colocação de grades metálicas, de malhas decrescentes, entre a fonte de luz e a câmara de troca gasosa. A intensidade zero foi conseguida com o envolvimento da câmara em papel alumínio.

Às idades de 2, 6 e 13 dias após a desfolha, mediu-se a taxa fotossintética de cada folha sob a intensidade luminosa de $2700 \mathrm{mmol} \cdot \mathrm{m}^{-2} \cdot \mathrm{s}^{-1}$. As medições foramfeitas entre 9 e 11 horas da manhã, utilizando um analisador infravermelho de gases, CIRAS - 1 (PP Systems), com fonte de luz própria. Os dados obtidos foram ajustados à equação abaixo, utilizando-se do programa estatístico SAS (1993), para a estimativa das constantes: FS máxima, Respiração e Eficiência fotossintética:

$$
\mathrm{Y}=\mathrm{a} *(1,0-\exp (-\mathrm{b} *(\mathrm{RFA} / \mathrm{a})))-\mathrm{R}
$$

em que: $\mathrm{Y}=$ taxa fotossintética $\left(\mathrm{mmol} \cdot \mathrm{m}^{-2} \cdot \mathrm{s}^{-1}\right) ; \mathrm{a}=$ fotossíntese máxima $\left(\mathrm{mmol} \cdot \mathrm{m}^{-2} \cdot \mathrm{s}^{-1}\right) ; \mathrm{b}=$ eficiência fotossintética; RFA = radiação fotossinteticamente ativa $\left(\mathrm{mmol} \cdot \mathrm{m}^{-2} \cdot \mathrm{s}^{-1}\right) ; \mathrm{R}=$ respiração $\left(\mathrm{mmol} \cdot \mathrm{m}^{-2} \cdot \mathrm{s}^{-1}\right)$;

Dosou-se também o teor de carboidratos não estruturais da base do colmo e das raízes, segundo Smith (1969).

Os dados experimentais foram submetidos à análise estatística, segundo o modelo:

$$
\mathrm{Y}_{\mathrm{ijk}}=\mathrm{m}+\mathrm{D}_{\mathrm{i}}+\mathrm{I}_{\mathrm{j}}+\mathrm{DI}_{\mathrm{ij}}+\mathrm{E}_{\mathrm{ijk}}
$$

em que: $\mathrm{Y}_{\mathrm{ijk}}=$ observação relativa ao $\mathrm{k}^{\mathrm{o}}$ vaso da $\mathrm{i}^{\mathrm{a}}$ desfolha na $\mathrm{j}^{\mathrm{a}}$ idade; $\mathrm{m}=$ média geral; $\mathrm{D}_{\mathrm{i}}=$ efeito da $\mathrm{i}^{\mathrm{a}}$ intensidade desfolha, $\mathrm{i}=1,2,3,4$; (fixo) $\mathrm{I}_{\mathrm{j}}=$ efeito da $j^{\mathrm{a}}$ idade, $\mathrm{j}=1,2,3$, 4; (fixo) $\mathrm{DI}_{\mathrm{ij}}=$ interação da $\mathrm{i}^{\mathrm{a}}$ intensidade de desfolha com a $\mathrm{j}^{\mathrm{a}}$ idade; $\mathrm{E}_{\mathrm{ijk}}=$ erro experimental.

As comparações das médias de tratamentos foram feitas pelo teste Tukey a $5 \%$ de probabilidade.

R. Bras. Zootec., v.31, n.6, p.2165-2175, 2002 


\section{Resultados e Discussão}

As condições do perfilho principal imediatamente após a imposição dos tratamentos são apresentadas na Tabela 1. As áreas foliares remanescentes, após as desfolhas inferior e superior, foram praticamente as mesmas, uma condição experimental desejável. Este fato explica-se pelo aumento do tamanho das folhas, à medida que se eleva o nível de inserção durante a fase inicial de desenvolvimento (Gomide \& Gomide, 2000).

Não foram observadas diferenças quanto à taxa respiratória, ponto de compensação de luz e eficiência fotossintética entre as folhas do perfilho principal, que apresentaram, ao tempo das desfolhas experimentais, a mesma curva de resposta à luz (Figura 2).

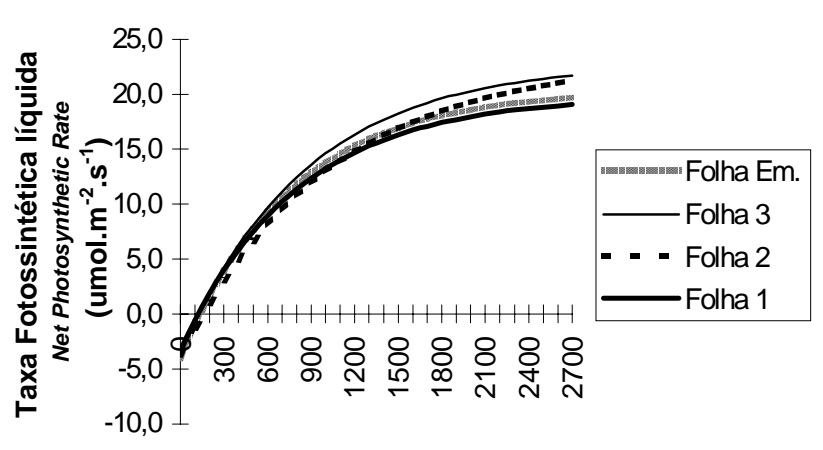

RFA (umol.m ${ }^{-2} \cdot s^{-1}$ )

Figura 2 - Curva fotossintética de resposta à luz de folhas individuais do perfilho principal ao tempo da desfolha.

Figure 2 - Photosynthetic response of individual leaves of the main tiller at defoliation time.
Taxas fotossintéticas máximas de 19,5;22; $21 \mathrm{e}$ $19,8 \mu \mathrm{mol}$ de $\mathrm{CO}_{2} \cdot \mathrm{m}^{-2} \cdot \mathrm{s}^{-1}$ foram observadas, respectivamente, para a folha emergente e folhas 3,2 e 1 (Figura 3), sem diferença estatística $(\mathrm{P}>0,05)$. Assim, a fotossíntese líquida máxima das folhas do perfilho principal (Figura 3) apresentou tendência de comportamento semelhante ao descrito na literatura, em que folhas mais jovens apresentam maior taxa fotossintética relativamente às mais velhas (Ryle \& Powell, 1975; Jewiss \& Woledge, 1967). Em plantas de Agropyron smithii, Painter \& Delting (1981) constataram redução de $10 \%$ na taxa fotossintética líquida da folha recém-expandida de perfilhos intactos em um intervalo de dez dias, evidenciando o efeito da idade da folha sobre sua taxa fotossintética.

As taxas de fotossíntese máxima observadas

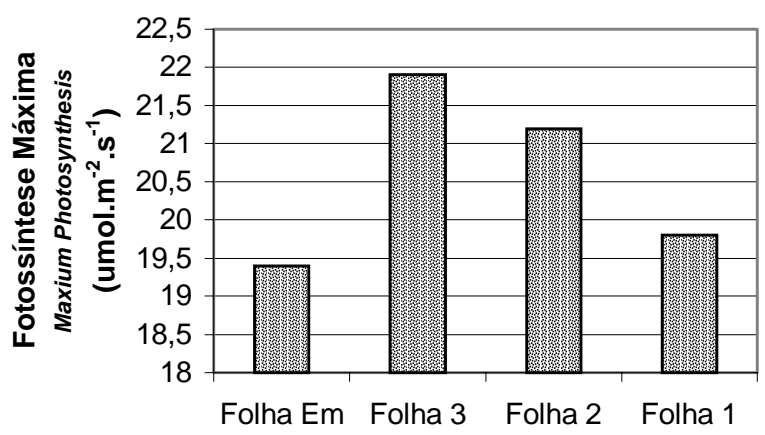

Figura 3 - Fotossíntese máxima das folhas do perfilho principal antes do corte.

Figure 3 - Maximum photosynthesis of the main tiller leaves before defoliation.

Tabela 1 - Folhas e área foliar deixadas no perfilho principal após a desfolha Table 1 - Leaves and leaf area remaining on the main tiller after defoliation

\begin{tabular}{|c|c|c|c|}
\hline \multirow[t]{2}{*}{$\begin{array}{l}\text { Tratamentos } \\
\text { Treatments }\end{array}$} & \multirow[t]{2}{*}{$\begin{array}{l}\text { Folhas deixadas }{ }^{1} \\
\text { Leaves remaining }\end{array}$} & \multicolumn{2}{|c|}{$\begin{array}{l}\text { Área foliar } \\
\text { Leaf area }\end{array}$} \\
\hline & & $\mathrm{cm}^{2}$ & $\%$ \\
\hline $\begin{array}{l}\text { Controle } \\
\text { Control }\end{array}$ & 1,2 , e 3 & 239 & 100 \\
\hline Desfolha total & - & 0 & 0 \\
\hline $\begin{array}{l}\text { Total defoliation } \\
\text { Desfolha inferior }\end{array}$ & 3 & 110 & 46 \\
\hline Lower defoliation & & & \\
\hline $\begin{array}{l}\text { Desfolha superior } \\
\text { Upper defoliation }\end{array}$ & 1 e 2 & 129 & 54 \\
\hline
\end{tabular}

${ }^{1}$ A folha 3 é recém-expandida e a folha 1 , a adulta mais velha.

13 stands for the newest expanded leave and 1 stands for the oldest adult leave.

R. Bras. Zootec., v.31, n.6, p.2165-2175, 2002 
neste trabalho correspondem aproximadamente a $57 \%$ da relatada para folhas de capim-sempre-verde (Panicum maximum) cultivado sob plena luminosidade (Ludlow \& Wilson, 1971). Visto que a fotossíntese máxima da folha é proporcional à intensidade luminosa reinante durante seu desenvolvimento (Ludlow \& Wilson, 1971; Woledge, 1971), as taxas ora relatadas refletiriam a condição de luminosidade subótima na casa de vegetação.

Multiplicando-se a fotossíntese máxima das folhas por suas respectivas áreas, estimou-se o potencial de fixação de $\mathrm{CO}_{2}$ por planta após a imposição dos tratamentos em: 1826; 957 e $869 \mu \mathrm{mol}$ de $\mathrm{CO}_{2} \cdot h^{-1}$, respectivamente, para os tratamentos: controle, desfolha superior e desfolha inferior.

Nos dias seguintes à desfolha (imposição dos tratamentos), observou-se aumento na taxa fotossintética máxima das folhas que escaparam ao corte (Figura 4), fenômeno também observado nas folhas das plantascontrole. Já no segundo dia, a máxima taxa fotossintética havia aumentado 14,20 e $38 \%$, respectivamente, para as folhas 3, 2 e 1 . Como a intensidade de desfolha não influenciou a magnitude do aumento, os dados representam a média dos valores para cada tipo de folha, independentemente do tratamento. $\mathrm{O}$ incremento perdurou até o sexto dia quando o percentual de aumento atingiu, respectivamente, 36,31 e $37 \%$.

Estudos de desfolhas em azevém (Lolium sp.) sugerem que o aumento na taxa fotossintética resulta de queda na resistência mesofílica à difusão do $\mathrm{CO}_{2}$ (Deinum, 1976). Marshall \& Sagar (1965) inferiram sobre a possibilidade do aumento na força dos novos

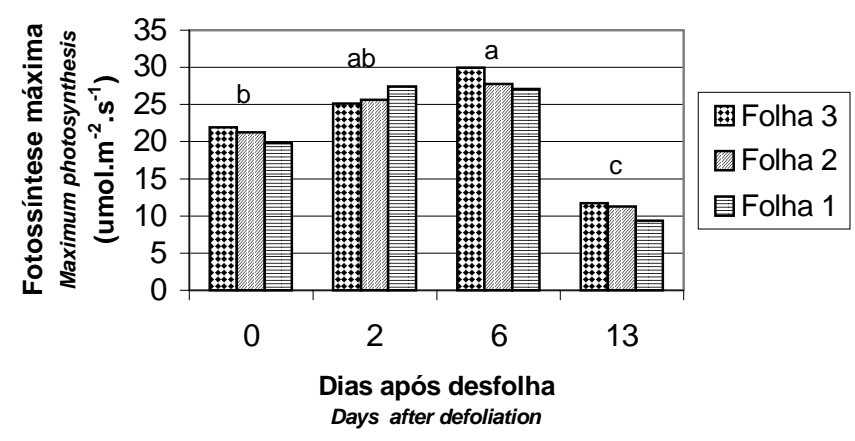

Figura 4 - Taxa fotossintética máxima das três folhas do perfilho principal, ao tempo da desfolha e nos dias seguintes, durante a rebrotação. Letras distintas expressam diferença pelo teste Tukey $(P<0,05)$.

Figure 4 - Maximum photosynthetic rate of the main tiller leaves, at the defoliation time and during regrowth. Different letters stand for difference by Tukey test $(P<.05)$. drenos gerados pela desfolha em estimular um aumento da assimilação das folhas remanescentes. Realmente, existem fortes evidências de que a taxa fotossintética da folha é influenciada pela demanda de assimilados e, se a demanda for baixa, o resultante acúmulo de açúcares ou amido na folha inibe a fotossíntese de maneira análoga à inibição por produtos finais nas reações bioquímicas. No presente caso, isto não se verificou, uma vezqueoaumentoocorreu independentemente da desfolha, até porque o corte dos perfilhos primários (realizado em todos os tratamentos) contribuiu para grande alteração na planta.

Grande redução ocorreu do sexto para o décimo terceiro dia, quando a fotossíntese máxima caiu, em média, para apenas $51 \%$ do valor observado ao tempo do corte. Isto poderia ser atribuído ao aumento na idade das folhas como discutido anteriormente, bem como a maior competição por nutrientes, água e hormônios com as novas folhas, uma vez que aos 16 dias de rebrota já se observava a presença de novas folhas tanto no perfilho principal como nos primários.

Painter \& Delting (1981) observaram aumento médio de $110 \%$ na taxa fotossintética líquida da folha mais jovem de Agropyron smithii nos dez dias posteriores à desfolha. Davies (1974) também sugere uma capacidade de aumento na taxa fotossintética das folhas remanescentes de azevém perene, que compensaria a perda parcial de tecido foliar. Entretanto, Ryle \& Powell (1975) observaram redução de 5 a $10 \%$ na taxa fotossintética das duas folhas baixeiras de cevada, remanescentes ao corte, quando comparada com plantas-controle.

Tabela 2 - Peso médio de novas folhas, por planta, em função dos tratamentos e das idades

Table 2 - Average weight of new leaves per plant related to treatments and ages

\begin{tabular}{|c|c|c|c|}
\hline $\begin{array}{l}\text { Tratamentos } \\
\text { Treatments }\end{array}$ & $\begin{array}{l}\text { Peso }(\mathrm{g}) \\
\text { Weight }(g)\end{array}$ & $\begin{array}{c}\text { Idade (dias) } \\
\text { Age (days) }\end{array}$ & $\begin{array}{c}\text { Peso }(\mathrm{g}) \\
\text { Weight }(g)\end{array}$ \\
\hline Controle & $2,40 \mathrm{~A}$ & 2 & $0,35 \mathrm{D}$ \\
\hline $\begin{array}{l}\text { Control } \\
\text { Desfolha inferior }\end{array}$ & $2,25 \mathrm{~A}$ & 5 & $1,15 \mathrm{C}$ \\
\hline $\begin{array}{l}\text { Lower leaves removed } \\
\text { Desfolha superior } \\
\text { Upper leaves removed }\end{array}$ & $2,19 \mathrm{~A}$ & 9 & $2,30 \mathrm{~B}$ \\
\hline $\begin{array}{l}\text { Desfolha total } \\
\text { Total defoliation }\end{array}$ & $1,86 \mathrm{~B}$ & 16 & $4,88 \mathrm{~A}$ \\
\hline
\end{tabular}

Médias seguidas de letras distintas diferem pelo teste Tukey $(\mathrm{P}<0,05)$.

Different letters stand for difference by Tukey test $(P<.05)$.

R. Bras. Zootec., v.31, n.6, p.2165-2175, 2002 
O crescimento de novas folhas foi avaliado tanto de forma absoluta, como em forma de taxas de crescimento relativo e de expansão da área foliar. O peso de novas folhas aumentou $(\mathrm{P}<0,05)$ com $\mathrm{o}$ avanço da rebrotação. Em grande parte, as novas folhas formadas após a imposição dos tratamentos tiveram sua origem nos perfilhos primários não decapitados pelo corte. Na Tabela 2, observa-se que apenas a desfolha total da planta comprometeu a produção de novas folhas, fato consistente com os relatos de Matches (1966) e Marshall \& Sagar (1965) sobre a assistência de perfilhos intactos na recuperação daqueles desfolhados. O benefício do perfilho intacto decorre da transporte de assimilados garantida pela continuidade de sua atividade fotossintética, talvez até rejuvenescida pelo corte. A ausência de significância $(P>0,05)$ para a diferença de peso de novas folhas da planta-controle e aquelas submetidas às desfolhas superior e inferior leva à sugestão de que até mesmo perfilhos retendo $50 \%$ de sua área foliar desempenha o mesmo papel na recuperação da planta.

Entretanto, a TCR de novas folhas não se alterou em função das desfolhas estudadas (Tabela 3), nem houve prejuízo para a taxa de aparecimento de folhas (dados não apresentados). Este resultado aparentemente contrasta com os dados de Davies (1974), que observou redução na taxa de aparecimento foliar com a remoção de todas as folhas e também das folhas superiores do perfilho de azevém perene, sendo a retirada das folhas superiores do perfilho a que mais afetou o aparecimento de novas folhas. Tal observação está de acordo com os relatos de Williams (1964) sobre o transporte preferencial de assimilados das folhas superiores para o meristema e folhas em expansão, enquanto as folhas baixeiras transportam para as raízes.

A divergência de comportamento observado no presente estudo pode ser atribuída à metodologia utilizada, em que as diferentes desfolhas foram aplicadas apenas ao perfilho principal, sendo os demais perfilhos cortados a $8 \mathrm{~cm}$. Assim, os dados apresentados não se referem a novas folhas surgidas no perfilho principal apenas, mas incluem também as novas folhas dos perfilhos primários, que representam a maioria delas. Dessa forma, o efeito das desfolhas pode ter sido diluído entre os demais perfilhos, conforme demonstrado nos trabalhos de Matches (1966) e Marshall \& Sagar (1968).

As plantas submetidas à desfolha total conseguiram, de certa forma, compensar o prejuízo para o crescimento em peso de novas folhas, revelando altas taxas de expansão da área foliar (Tabela 4). Este mecanismo garantiu às plantas sob desfolha total área foliar semelhante aos demais tratamentos após 16 dias de rebrota: $1319,1259,1145$ e $1187 \mathrm{~cm}^{2}$, respectivamente, para o controle, desfolha total, desfolha superior e desfolha inferior.

Verificou-se a interação intensidade de desfolha e idade de rebrota sobre a evolução do sistema radicular da gramínea (Figura 5). O sistema radicular cresceu linearmente durante os primeiros 16 dias de rebrota, segundo coeficientes lineares de $0,056 \mathrm{e}$ $0,136 \mathrm{~g} /$ dia em plantas submetidas à desfolha total $\mathrm{e}$ qualquer um dos demais tratamentos, respectivamente.

Tabela 3 - Taxa de crescimento relativo $\left(\mathrm{g} \cdot \mathrm{g}^{-1} \cdot \mathrm{dia}^{-1}\right)$ de novas folhas do perfilho principal e dos perfilhos primários

Table 3 - Relative growth rate $\left(g \cdot g^{-1} \cdot d^{d i a}{ }^{-1}\right)$ of new leaves of de main and primary tillers

\begin{tabular}{|c|c|c|}
\hline $\begin{array}{l}\text { Tratamentos } \\
\text { Treatments }\end{array}$ & $\begin{array}{l}\text { erfilho principal } \\
\text { Main tiller }\end{array}$ & $\begin{array}{c}\text { Perfilhos primários } \\
\text { Primary tillers }\end{array}$ \\
\hline $\begin{array}{l}\text { Desfolha total } \\
\text { Total defoliation }\end{array}$ & 0,185 & 0,208 \\
\hline $\begin{array}{l}\text { Controle } \\
\text { Control }\end{array}$ & 0,159 & 0,206 \\
\hline $\begin{array}{l}\text { Desfolha superior } \\
\text { Upper leaves removed }\end{array}$ & 0,158 & 0,187 \\
\hline $\begin{array}{l}\text { Desfolha inferior } \\
\text { Lower leaves removed }\end{array}$ & ed & - \\
\hline
\end{tabular}

Tabela 4 - Taxa de expansão da área foliar $\left(\mathrm{cm}^{2} \cdot \mathrm{dia}^{-1}\right)$ do perfilho principal e de toda a planta durante os 16 dias de rebrota

Table 4 - Leaf area expansion rate $\left(\mathrm{cm}^{2} . \mathrm{dia}^{-1}\right)$ of the main tiller and whole plant over 16 days of regrowth

\begin{tabular}{|c|c|c|}
\hline $\begin{array}{l}\text { Tratamentos } \\
\text { Treatments }\end{array}$ & $\begin{array}{l}\text { Perfilho principal } \\
\text { Main tiller }\end{array}$ & $\begin{array}{l}\text { Planta inteira } \\
\text { Whole plant }\end{array}$ \\
\hline $\begin{array}{l}\text { Desfolha total } \\
\text { Total defoliation }\end{array}$ & $16,6 \mathrm{~A}$ & $80,6 \mathrm{~A}$ \\
\hline $\begin{array}{l}\text { Desfolha inferior } \\
\text { Lower leaves removed }\end{array}$ & $16,2 \mathrm{AB}$ & $67,6 \mathrm{AB}$ \\
\hline $\begin{array}{l}\text { Controle } \\
\text { Control }\end{array}$ & $14,0 \mathrm{AB}$ & $66,0 \mathrm{AB}$ \\
\hline $\begin{array}{l}\text { Desfolha superior } \\
\text { Upper leaves removed }\end{array}$ & $12,2 \mathrm{~B}$ & $62,0 \mathrm{~B}$ \\
\hline
\end{tabular}

Médias seguidas de letras distintas diferem pelo teste Tukey $(\mathrm{P}<0,05)$.

Different letters stand for difference by the Tukey test $(P<.05)$. 


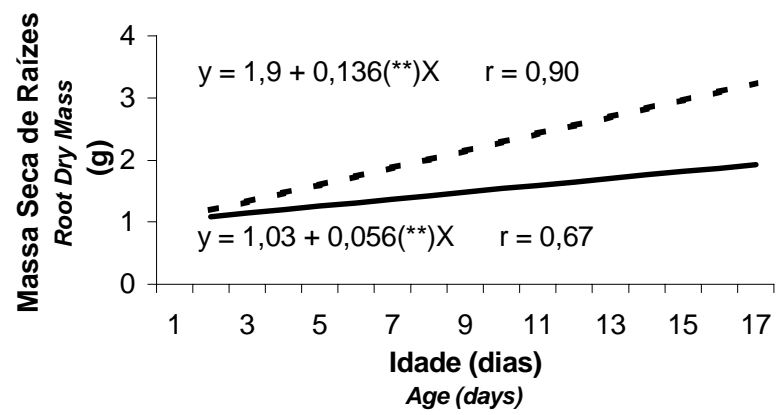

Figura 5 - Evolução do peso de raízes de plantas sob os tratamentos: controle, desfolha superior e inferior (-----) e sob desfolha total $(\underline{-0})$ durante o período de rebrotação. $\left(^{* *}\right) \mathrm{P}<0,01$.

Figure 5 - Evolution of root weight of plants under the control, bottom and top defoliation (------) and total defoliation ( $(-)$ treatments during the regrowth period. $\left.{ }^{* *}\right) P<.01$

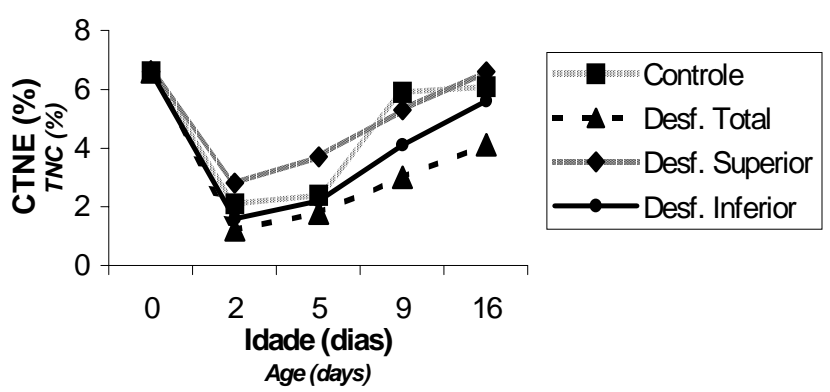

Figura 6 - Teores médios de carboidratos totais não estruturais (CTNE) da base do colmo ao longo do período de rebrota em função das desfolhas.

Figure 6 - Average values of the total nonstructural carbohydrates (TNC) of the stem base during the regrowth, according to the defoliation treatment.

Esta redução no crescimento do sistema radicular das plantas totalmente desfolhadas é o reflexo do prejuízo causado à taxa de crescimento relativo do sistema radicular das plantas totalmente desfolhadas, que foi de apenas 50\% daquela observada para os demais tratamentos $\left(0,03 \times 0,06 \mathrm{~g} \cdot \mathrm{g}^{-1} \cdot \mathrm{dia}^{-1}\right)$.

A mais baixa taxa de crescimento do sistema radicular das plantas sob desfolha total é consistente com seus mais baixos teores de carboidratos totais não-estruturais (CTNE).

O menor incremento do sistema radicular das plantas sob regime de desfolha total ao longo dos 16 dias de rebrotação (Figura 5) evidencia o grande estresse infligido à planta. Por outro lado, a presença do perfilho principal intacto (controle) ou apenas parcialmente desfolhado (desfolhas superior ou inferior) foi suficiente para dar suporte ao crescimento radicular.

A inexistência de diferenças de resposta de crescimento do sistema radicular às desfolhas superior $\mathrm{e}$ inferior do perfilho principal, relativamente ao controle, permite concluir que a manutenção de $50 \%$ da área foliar do perfilho principal foi suficiente para garantir, ou pelo menos não comprometer, o crescimento do sistema radicular.

Após o corte, há diminuição no transporte de assimilados para as raízes (Marshall \& Sagar, 1965; Ryle \& Powell, 1975; Frankow-Lindberg, 1997; De Visser et al., 1997) em prol da pronta recuperação da área foliar. Segundo Donaghy \& Fulkerson (1998), é importante que, após o corte, as raízes tenham menor prioridade em relação ao crescimento foliar a fim de restabelecer a capacidade fotossintética da planta e prevenir o esgotamento das reservas.

Os resultados obtidos no presente estudo evidenciam que a restrição inicial de assimilados da fotossíntese, após a desfolha total, comprometeu o crescimento radicular. Nos demais tratamentos, a pronta disponibilidade de assimilados da fotossíntese atual teria permitido o transporte mais precoce para as raízes, ou possibilitado a elas uma menor dependência das reservas orgânicas. Em plantas de trevo branco submetidas a duas intensidades de desfolha, Frankow-Lindberg (1997) observou maior exportação para o ápice às custas do estolão principal, quando se deixou apenas uma folha expandida. De Visser et al. (1997) observaram que, após uma semana de rebrota, os fotoassimilados responderam por 90\% da matéria seca presente na zona de alongamento foliar de azevém perene.

Desde que, neste estudo, foram dadas condições favoráveis de crescimento às plantas (água e nutrientes), o prejuízo para a rebrotação, embora perceptível, como será visto a partir de outras variáveis, poderia ser ainda mais acentuado. Isto realça a importância da adoção de manejos que atendam às exigências das plantas forrageiras para uma boa recuperação.

Os valores dos índices TCR, TAL e RAF, apresentados na Tabela 5, resultam da média dos cinco vasos de cada tratamento, pois, dada a presença de apenas uma planta por vaso, este procedimento possibilitou melhor ajuste das equações de peso e área foliar em relação às idades.

Os valores de TCR da planta inteira (Tabela 5) são inferiores àqueles da TCR de novas folhas

R. Bras. Zootec., v.31, n.6, p.2165-2175, 2002 


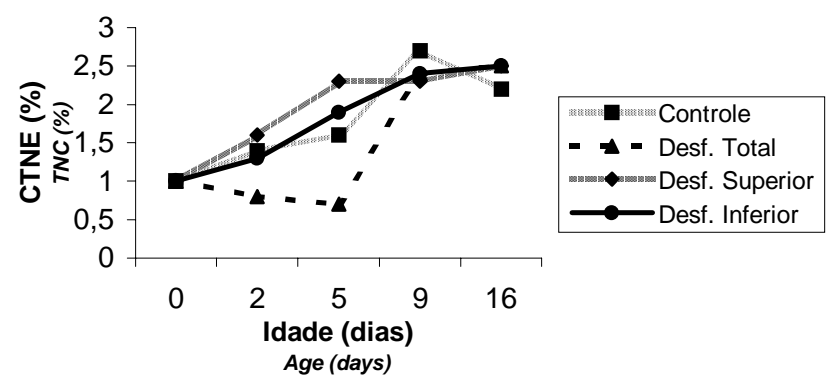

Figura 7 - Teores médios de carboidratos totais não estruturais (CTNE) das raízes ao longo do período de rebrota, em função das desfolhas.

Figure 7 - Average values of the root total nonstructural carbohydrates (TNC) during the regrowth, as affected by defoliation treatments.
(Tabela 3), o que realça a primazia da parte aérea por assimilados após o corte.

A taxa de crescimento relativo foi maior nas idades intermediárias, devido ao aumento na RAF (Tabela 5). Entretanto, devido ao aumento substancial do peso de toda a planta aos 16 dias, a RAF tendeu a cair, provocando redução na TCR. As plantas submetidas à desfolha total rapidamente recuperaram sua RAF, mantendo-a alta a partir do quinto dia. Tal fato pode ser explicado pelo menor peso total das plantas deste tratamento, relativamente aos demais, bem como pelo maior investimento na expansão da área foliar, como mostrado na Tabela 4.

O mais baixo valor da TAL, observado no segundo dia de rebrotação das plantas totalmente desfolhadas, refletiria intensa perda respiratória pro-

Tabela 5 - Valores instantâneos de taxa de crescimento relativo (TCR), taxa assimilatória líquida (TAL) e razão de área foliar (RAF) durante a rebrota do capim-mombaça submetido a diferentes tratamentos de desfolha

Table 5 - Instantaneous values of relative growth rate (RGR), net assimilation rate (NAR) and leaf area ratio (LAR) during regrowth period of Mombaçagrass under different defoliation treatments

\begin{tabular}{|c|c|c|c|c|}
\hline \multirow[t]{2}{*}{$\begin{array}{l}\text { Tratamentos } \\
\text { Treatments }\end{array}$} & \multicolumn{4}{|c|}{ Idade (dias) } \\
\hline & 2 & 5 & 9 & 16 \\
\hline & \multicolumn{4}{|c|}{$\begin{array}{l}\text { TCR }\left(\mathrm{g} \cdot \mathrm{g}^{-1} \cdot \mathrm{dia}^{-1}\right) \\
R G R\left(\text { g. } g^{-1} \cdot \text { day }^{-1}\right)\end{array}$} \\
\hline $\begin{array}{l}\text { Controle } \\
\text { Control }\end{array}$ & 0,079 & 0,087 & 0,087 & 0,073 \\
\hline $\begin{array}{l}\text { Desfolha total } \\
\text { Total defoliation }\end{array}$ & 0,017 & 0,065 & 0,095 & 0,091 \\
\hline $\begin{array}{l}\text { Desfolha superior } \\
\text { Upper leaves removed }\end{array}$ & 0,066 & 0,085 & 0,091 & 0,079 \\
\hline $\begin{array}{l}\text { Desfolha inferior } \\
\text { Lower leaves removed }\end{array}$ & 0,055 & 0,082 & 0,092 & 0,082 \\
\hline & \multicolumn{4}{|c|}{$\begin{array}{l}\text { TAL }\left(\mathrm{g} \cdot \mathrm{m}^{-2} \cdot \mathrm{dia}^{-1}\right) \\
\operatorname{NAR}\left(g \cdot \mathrm{m}^{-2} \cdot \mathrm{day}^{-1}\right)\end{array}$} \\
\hline $\begin{array}{l}\text { Controle } \\
\text { Control }\end{array}$ & 9,5 & 7,8 & 7,7 & 9,1 \\
\hline $\begin{array}{l}\text { Desfolha total } \\
\text { Total defoliation }\end{array}$ & 5,0 & 7,3 & 7,8 & 8,0 \\
\hline $\begin{array}{l}\text { Desfolha superior } \\
\text { Upper leaves removed }\end{array}$ & 9,8 & 8,4 & 8,4 & 10,0 \\
\hline $\begin{array}{l}\text { Desfolha inferior } \\
\text { Lower leaves removed }\end{array}$ & 9,3 & 8,3 & 8,5 & 10,0 \\
\hline & \multicolumn{4}{|c|}{$\begin{array}{l}\operatorname{RAF}\left(\mathrm{m}^{2} \cdot \mathrm{kg}^{-1}\right) \\
\operatorname{LAR}\left(m^{2} \cdot \mathrm{kg}^{-1}\right)\end{array}$} \\
\hline $\begin{array}{l}\text { Controle } \\
\text { Control }\end{array}$ & 8,3 & 11,0 & 11,0 & 8,0 \\
\hline $\begin{array}{l}\text { Desfolha total } \\
\text { Total defoliation }\end{array}$ & 3,4 & 9,0 & 12,0 & 11,0 \\
\hline $\begin{array}{l}\text { Desfolha superior } \\
\text { Upper leaves removed }\end{array}$ & 6,7 & 10,0 & 10,0 & 8,0 \\
\hline $\begin{array}{l}\text { Desfolha inferior } \\
\text { Lower leaves removed }\end{array}$ & 5,9 & 10,0 & 10,0 & 8,0 \\
\hline
\end{tabular}

R. Bras. Zootec., v.31, n.6, p.2165-2175, 2002 
porcionalmente à fixação de carbono então limitada pela pequena área foliar, fato que também levou a um baixo valor da RAF e, conseqüentemente, a um comprometimento da TCR. Ryle \& Powell (1975) não observaram diferença na TCR de plantas de cevada parcialmente desfolhadas e aquelas mantidas intactas. Por sua vez, Davies (1974), avaliando a remoção de diferentes folhas dos perfilhos de azevém perene, observou comprometimento da TCR apenas quando da remoção de todas as folhas do perfilho. Neste estudo, também não se observou diferença $(\mathrm{P}>0,05)$ na TCR de plantas submetidas às desfolhas superior e inferior e nas plantas-controle.

O aumento da TAL nas idades seguintes, após a desfolha total, decorreria do aumento progressivo da área foliar até os 16 dias. Nos demais tratamentos, os valores da TAL ficaram praticamente estáveis ao longo do período de rebrotação estudado, demonstrando que o crescimento da nova área foliar, de alta eficiência assimilatória (Woledge \& Leafe, 1976; Parsons et al., 1983), compensou o aumento total de peso da planta, já que este índice é o resultado do balanço entre fotossíntese e respiração (Lambers et al., 1989).

O teor de carboidratos totais não-estruturais na base do colmo foi influenciado pelos tratamentos $(\mathrm{P}<0,05)$ e pelo tempo de rebrotação $(\mathrm{P}<0,05)$. Nota-se queda acentuada no teor destas substâncias logo no segundo dia de rebrota, com recuperação a partir do quinto dia, contudo sem restabelecimento dos teores iniciais após 16 dias, principalmente sob a desfolha total (Figura 6). Fulkerson \& Slack (1994) relatam participação dos carboidratos de reserva na rebrota de azevém perene até o sexto dia, momento em que se completou a expansão da primeira folha. Redução nos teores de carboidratos totais não-estruturais, nos dias subseqüentes ao corte, foi observada em capim-jaraguá (Botrel \& Gomide, 1981) e em Festuca arundinacea (Volenec, 1986). Da mesma forma, Schnyder \& De Visser (1999) relatam redução nos teores de carboidratos solúveis logo após o corte em plantas de azevém perene. Porém, segundo esses autores, a participação desses compostos no crescimento dos perfilhos foi mínima após o primeiro dia de rebrota.

A redução do teor de CTNE ocorreu independentemente dos tratamentos de desfolha, mas foi mais intensa sob desfolha total relativamente à desfolha superior e ao controle. $\mathrm{O}$ fato de a redução ter ocorrido em todos os tratamentos é interpretado como indicação de que os assimilados gerados não foram suficientes para suprir o crescimento de novas folhas e a respiração da planta. Embora não se tenha avaliado a efetiva participação dos carboidratos na formação de novas estruturas, a redução observada após o corte é, de qualquer modo, um indício de sua contribuição para a manutenção da planta após o corte.

Em capim-colonião, a recuperação das reservas de carboidratos não estruturais após o corte tem sido observada por volta do $21^{\circ}$ dia de rebrota (Gomide \& Zago, 1980; Nascimento et al., 1980), atingindo teores ligeiramente mais elevados do que os desse estudo. Além da espécie, esta diferença poderia estar relacionada à metodologia, uma vez que, no presente estudo, a desfolha se deu no início do desenvolvimento das plantas, por volta do $35^{\circ}$ dia após a emergência das plantas.

As raízes apresentaram teores mais baixos de carboidratos de reserva (Figura 7). Esta observação é consistente com o relato da literatura, de que, em gramíneas o principal órgão de reserva é a base do colmo (Davies, 1974; Nascimento et al., 1980). Observa-se o efeito da idade sobre o teor de CTNE das raízes, como observado para a base do colmo. Porém, apenas na desfolha total ocorreu redução no teor de CTNE das raízes às idades de 2 e 5 dias após o corte, sendo que, ao contrário do observado para a base do colmo, aos 16 dias, já havia igualdade entre os tratamentos (Figura 7). Esta observação poderia indicar uma contribuição das reservas das raízes sob condições de desfolha mais drástica. Entretanto, como o valor médio no momento do corte era de apenas $1,0 \%$, parece mais plausível considerar estes baixos valores como maior prejuízo ao desenvolvimento das raízes sob a desfolha mais intensa, conforme se observa na Figura 5.

Segundo Davidson \& Milthorpe (1966), Marshall \& Sagar (1965) e Ryle \& Powell (1975), o carbono das raízes não é translocado, sendo utilizado para a respiração e recuperação do estresse causado pelo corte. Da mesma forma, para Davies (1988), não há evidências do transporte de carbono das raízes para os pontos de crescimento após desfolha em gramíneas não rizomatosas. Entretanto, Johansson (1993), estudando a distribuição de carbono durante a rebrota de Festuca pratensis, relata transporte tanto da base do colmo como das raízes.

Estudando a importância das reservas de carboidratos solúveis na rebrota de azevém perene, Donaghy \& Fulkerson (1997) observaram maiores reduções destes compostos, à medida que se aumentou a freqüência das desfolhas. O mesmo comporta-

\section{R. Bras. Zootec., v.31, n.6, p.2165-2175, 2002}


mento foi observado por Slack et al. (2000) estudando a rebrotação de Bromus wildenowii e Lolium perenne.

Uma desfolha mais intensa, em que se elimina grande quantidade de área foliar, levando à maior redução da capacidade fotossintética, torna a rebrota mais dependente das reservas. No presente estudo avaliou-se apenas a variação da intensidade de desfolha do perfilho principal, sendo os demais perfilhos cortados. Assim, o efeito da desfolha do perfilho principal não pôde ser observado com clareza. De qualquer forma, observou-se que as plantas submetidas à desfolha total apresentaram teor de CTNE inferior àquelas submetidas a desfolha menos intensa.

\section{Conclusões}

As três folhas adultas do perfilho principal não diferiram quanto à fotossíntese máxima, que experimentou aumento nos primeiros dias após a desfolha e queda acentuada já no $13^{\circ}$ dia.

A desfolha total da planta comprometeu seu sistema radicular e sua concentração de CTNE. Porém, estas plantas conseguiram, em parte, compensar o prejuízo para a rebrota, aumentando seu investimento no crescimento de área foliar, revelando maiores valores para a taxa de expansão da área foliar e RAF.

A presença de um perfilho intacto, ou apenas parcialmente desfolhado, favoreceu a pronta recuperação da planta após desfolha.

A imposição dos regimes de desfolha em todos os perfilhos da planta teria permitido maior contraste entre os tratamentos e melhor identificação dos mecanismos de rebrotação.

\section{Literatura Citada}

BOTREL, M.A.; GOMIDE, J.A. Importância do teor de carboidratos de reserva e da sobrevivência dos meristemas apicais para a rebrota do capim-jaraguá (Hyparrhenia rufa). Revista da Sociedade Brasileira de Zootecnia, v.10, n.3, p.411-426, 1981.

BROUGHAM, R.W. Effect of intensity of defoliation on regrowth of pasture. Australian Journal of Agricultural Research, v.7, n.5, p.377-387, 1956.

DAVIDSON, J.L.; MILTHORPE, F.L. The effect of defoliation on the carbon balance in Dactylis glomerata. Annals of Botany, v.30, n.118, p.185-198, 1966.

DAVIES, A. The regrowth of grass swards. In: JONES, M.B.; LAZENBY, A. (Eds.) The grass crop. London: Chapman and Hall, 1988. p.85-127. DAVIES, A. Leaf tissue remaining after cutting and regrowth in perennial ryegrass. Journal of Agriculture Science, v.82, p.165-172, 1974.
DE VISSER, R.; VIANDER, H.; SCHNYDER, H. Kinetics and relative significance of remobilized and current $\mathrm{C}$ and $\mathrm{N}$ incorporation in leaf and root growth zones of Lolium perenne after defoliation: assessment by ${ }^{13} \mathrm{C}$ and ${ }^{15} \mathrm{~N}$ steady-state labelling. Plant, Cell and Environment, v.20. p.37-46, 1997.

DEINUM, B. Photosynthesis and sink size: An explanation for the low productivity of grass sward in autumn. Netherlands Journal of Agriculture Science, v.24, p.238-246, 1976. DELTING, J.K.; DYER, M.I.; WINN, D.T. Net photosynthesis, root respiration and regrowth of Bouteloua gracilis following grazing. Oecologia, v.41, p.127-134, 1979.

DONAGHY, D.J.; FULKERSON, W.J. The importance of watersoluble carbohydrate reserves on regrowth and root growth of Lolium perenne. Grass and Forage Science, v.52, n.4, p.401-407, 1997.

DONAGHY, D.J.; FULKERSON, W.J. Priority for allocation of water-soluble carbohydrate reserves during regrowth of Lolium perenne. Grass and Forage Science, v.53, n.3, p.211-218, 1998.

FRANKOW-LINDBERG, B.E. Assimilate partioning in three white clover cultivars in the autumn, and the effect of defoliation. Annals of Botany, v.79, p.83-87, 1997.

FULKERSON, W.J.; SLACK, K. Leaf number as a criterion for determining defoliation time for Lolium perenne. 1 . Effect of water soluble carbohydrate, and senescence. Grass and Forage Science, v.49, n.4, p.373-377, 1994.

FULKERSON, W.J.; SLACK, K. Leaf number as a criterion for determining defoliation time for Lolium perenne. 2 . Effect of defoliation frequency and height. Grass and Forage Science, v.50, n.1, p.16-20, 1995.

GOMIDE, C.A.; GOMIDE, J.A. Morfogênese de cultivares de Panicum maximum. Revista Brasileira de Zootecnia, v.29, n.2, p.341-348, 2000.

GOMIDE, J.A.; ZAGO, C.P. Crescimento e recuperação do capim-colonião após corte. Revista da Sociedade Brasileira de Zootecnia, v.9, n.2, p.293-305, 1980.

JEWISS, O.R.; WOLEDGE, J. The effect of age on the rate of apparent photosynthesis in leaves of tall fescue (Festuca arundinacea Schreb.) Annals of Botany, v.31, n.124, p.661671, 1967.

JOHANSSON, G. Carbon distribuition in grass (Festuca arundinacea) during regrowth after cutting - Utilization of stored and newly assimilated carbon. Plant and Soil, v.151, n.1, p.11-20, 1993.

LAMBERS, H.; FREIDJSEN, N.; POORTER, H. Analysis of growth based on net assimilation rate and nitrogen productivity. Their physiological background. In: LAMBERS, H., CAMBridge, M.L., KONINGS, H. et al. (Ed.) Causes and consequences of variation in growth rate and productivity of higher plants. Hauge: Netherlands. 1989. p.1-17.

LUDLOW, M.W.; WILSON, G.L. Photosynthesis of tropical pasture plants. II. Temperature and iluminance history. Australian. Journal of Biology Science, v.24, p.10651075, 1971.

MARSAHLL, C.; SAGAR, G.R. The interdependence of tillers in Lolium multiflorum: A quantitative assessment. Journal of Experimental Botanny, v.19, n.61, p.785-794, 1968. MARSAHLL, C.; SAGAR, G.R. The influence of defoliation on the distribution of assimilates in Lolium multiflorum. Annals of Botany, v.29, n.115, p.365-372, 1965.

MATCHES, A.G. Influence of intact tillers and height of stuble

R. Bras. Zootec., v.31, n.6, p.2165-2175, 2002 
on growth responses of tall fescue. (Festuca arundinacea). Crop Science, v.6, n.5, p.484-487, 1966.

NASCIMENTO, M.P.S.C.B.; NASCIMENTO, H.T.S.; GOMIDE, J.A. Alguns aspectos morfológicos de três gramíneas de clima tropical. Revista da Sociedade Brasileira de Zootecnia, v.9, n.1, p.142-158, 1980.

PARSONS, A.J.; LEAFE, E.F.; COLLET, B. et al. The physiology of grass production under grazing: 1 - Characteristics of leaf and canopy photosynthesis of continuously grazed sward. Journal of Applied Ecology, v.20, n.1, p.117-126, 1983.

PAINTER, E.L.; DELTING, J.K. Effects of defoliation on net photosynthesis and regrowth of western wheatgrass. Journal of Range Management, v.34, n.1, p.68-71, 1981.

RADFORD, P.J. Growth analysis formulae: their use and abuse. Crop Science, v.7, n.3, p.171-175, 1967.

RICHARDS, J.H. Physiology of plants recovering from defoliation. In: BAKER, M.J. (Ed.) Grassland for our world. Wellington: SIR Publishing, 1993. p.46-54.

RYLE, G.J.A.; POWELL, C.E. Defoliation and regrowth in the graminaceous plant: The role of current assymilate. Annals of Botany, v.39, n.160, p.297-310, 1975.

SAS INSTITUTE. SAS/STAT user' s guide: statistics. 4 ed. Version 6. Cary: 1993. 943p.

SCHNYDER, H.; DE VISSER, R. Fluxes of reserve-derived and currently assimilated carbon and nitrogen in perennial ryegrass recovering from defoliation. The regrowing tiller and its component functionally distinct zones. Plant Physiology, v.119, p.1423-1435, 1999.

SLACK, K.; FULKERSON, W.J.; SCOTT, J.M. Regrowth of prairie grass (Bromus willdenwii Kunth) and perennial ryegrass (Lolium perenne L.) in response to temperature and defoliation. Australian Journal of Agriculture Research, v.51, p.555-561, 2000.
SMITH, D. Removing and analyzing total non structural carbohydrates from plant tissue. Wisconsin: University of Wisconsin, 1969. 11p. (Research report, 41)

SMITH, L.H.; MARTEN, G.C. Foliar regrowth of alfafa utilizing ${ }^{14} \mathrm{C}$-labeled carbohydrates stored in roots. Crop Science, v.10, n.2, p.146-150, 1970.

VOLENEC, J.J. Nonstructural carbohydrates in stem base components of tall fescue during regrowth. Crop Science, v.26, p.122-127, 1986.

WARD, C.Y.; BLASER, R.E. Carbohydrates food reserves and leaf area in regrowth of orchardgrass. Crop Science, v.1, n.5, p.366-370, 1961.

WILLIAMS, R.D. Assimilation and translocation in perennial grasses. Annals of Botany, v.28, n.11, p.419-429, 1964.

WOLEDGE, J. The effect of light intensity during growth on the subsequent rate of photosynthesis of leaves of tall fescue (Festuca arundinacea). Annals of Botany, v.35, n.140, p.311-322, 1971.

WOLEDGE, J.; LEAFE, E.L. Single leaf and canopy photosynthesis in a ryegrass sward. Annals of Botany, v.40, n.68, p.773-783, 1976.

Recebido em: 31/12/01

Aceito em: 27/05/02 